\title{
Prognostic indicators of the outcome of meningococcal disease: a study of 562 patients
}

\author{
MARIËTTE C. LODDER, REGINA L. SCHILDKAMP, H. A. BIJLMER*, J. DANKERT†, D. J. KUIK + and \\ R. J. P. M. SCHOLTEN§
}

Institute for Research in Extramural Medicine, Vrije Universiteit, Amsterdam, *Hospital "Bronovo", The Hague, †Netherlands Reference Laboratory for Bacterial Meningitis, WHO Collaborating Centre, University of Amsterdam/National Institute for Public Health and Protection, Amsterdam and ${ }^{\ddagger}$ Department of Epidemiology and Biostatistics, Vrije Universiteit, Amsterdam, The Netherlands

To assess prognostic indicators of a fatal outcome in patients with meningococcal disease, data from 562 patients with culture-proven meningococcal disease, reported in the Netherlands between 1 April 1989 and 30 April 1990, were collected prospectively by means of a questionnaire completed by the specialist in attendance. Analysis was done by the $\chi^{2}$ test and multiple logistic regression. During the study period 43 patients $(7.7 \%)$ died. The risk of a fatal outcome was increased in patients aged 0-5 months, 10 19 years, and $\geqslant 50$ years, in female patients and in patients presenting with coma, temperature $\leqslant 38.0^{\circ} \mathrm{C}$, mean arterial pressure $\leqslant 70 \mathrm{mmHg}$, white blood cell count $\leqslant 10 \times 10^{9} / \mathrm{L}$ and platelet count $\leqslant 100 \times 10^{9} / \mathrm{L}$. Predisposing factors and duration of disease before admission were significantly associated with outcome, but these associations disappeared in the multivariate analysis. Race, the administration of antibiotics prior to admission, seizures and haemorrhagic skin lesions were not associated with outcome. In conclusion age, gender, coma, temperature, mean arterial pressure, white blood cell count and platelet count were independent prognostic indicators of the outcome of meningococcal disease. The assessment of these characteristics may be helpful for the identification of high risk patients, whose prognosis might be improved by prompt transfer to an intensive care unit.

\section{Introduction}

Meningococcal disease (MD) is still prevalent throughout the world and remains a serious health problem [1]. The reported case-fatality rates (CFR) of MD range from 5 to $16 \%[2-11]$. An apparently healthy person who contracts MD might die within $24 \mathrm{~h}$, and improvements of patient care during the last four decades have had no measurable impact on the CFR of MD [10].

Clinical parameters at presentation have been used to develop prognostic scores to estimate the chance of a fatal outcome $[6,7,9,11-15]$. The identification of parameters associated with a fatal outcome may result in the early recognition of patients needing aggressive therapy, which may have a favourable influence on their prognosis.

From 1982 onwards, a gradual increase in the incidence of MD in the Netherlands was noted [16],

Received 13 April 1995; revised version accepted 29 November 1995.

§Corresponding author: Dr. R. J. P. M. Scholten. and a nation-wide survey was started in 1989. During a 13-month period the meningococcal isolates and data from 562 culture-proven cases of MD were collected. The bacteriological characteristics of the meningococci isolated from these patients, and their relationship with the disease outcome have been described elsewhere $[17,18]$. This report presents the analysis of the relationship between clinical determinants and the outcome of MD.

\section{Patients and methods}

Since 1958, isolates of Neisseria meningitidis from the blood or cerebrospinal fluid (CSF), or both, of patients with MD have been sent to the Netherlands Reference Laboratory for Bacterial Meningitis (RLBM) in Amsterdam by regional laboratories. During the study period from 1 April 1989 until 30 April 1990, 563 consecutive patients with culture-proven MD were reported. $N$. meningitidis was cultured from the CSF in 325 of the patients $(57.7 \%)$, from the blood in 115 patients $(20.4 \%)$, and from both CSF and blood in 123 patients $(21.8 \%)$. 
Immediately after receipt of the isolate, the attending specialist was contacted and asked to complete a questionnaire which included, among others, questions about the presence of predisposing factors, duration of disease before admission, the administration of antibiotics immediately prior to admission, signs, symptoms and laboratory parameters on admission (coma, seizures, haemorrhagic skin lesions, blood pressure, temperature, WBC count and platelet count). Four weeks later a follow-up questionnaire regarding the disease outcome was sent to the attending specialist. No information was provided for one patient; thus, data from 562 patients could be analysed.

Predisposing factors were defined as the presence of malignancy, immunosuppressive therapy, diabetes mellitus, chronic obstructive lung disease, chronic renal failure, liver cirrhosis, intravenous drug-abuse, recent severe head injury and a history of neurosurgery.

The mean arterial pressure (MAP) was calculated by the formula: two-thirds of the diastolic blood pressure plus one-third of the systolic blood pressure.

Age was classified into five functional categories which represent homogeneous age groups with respect to the CFR. The age ranges of these categories were chosen to enhance statistical efficiency. The category 6 months-9 years served as reference category. Duration of disease before admission and the numerical variables temperature, MAP, WBC count and platelet count were dichotomised.

The association of each individual variable with the disease outcome was assessed by the $\chi^{2}$ test. Fisher's exact test was used when appropriate. The relative risk of a fatal outcome was expressed as an odds ratio (OR) with its $95 \%$ confidence interval (CI). Exact CIs were calculated when appropriate.

The most important clinical prognostic indicators of a fatal outcome were determined by multiple logistic regression. All variables that were associated with the disease outcome in the univariate analysis (threshold $p=0.20$ ) were selected for multivariate analysis. The model was fitted by forward selection of individual variables (significance level $\mathrm{p}=0.05$ ).

Before entering into the logistic model, for each variable with missing values an indicator term was constructed which indicated the presence $(\operatorname{code}=1)$ or absence (code $=0$ ) of information of the corresponding variable. Product terms were constructed of each indicator and its corresponding variable. Instead of the individual variables, the combination of each product term and the corresponding indicator of available information was entered into the logistic model. By the use of this strategy, patients with missing values of one or more variables could be included in the analysis. The estimated coefficients of the variables with missing values pertained to those patients for whom information was present, whereas the other coefficients pertained to all patients [19].

All analyses were done with the statistical packages SPSS-PC $^{R}$ and EPI-INFO ${ }^{R}$.

\section{Results}

During the study period, 43 of the 562 patients died $(\mathrm{CFR}=7.7 \%)$. In the univariate analysis, age, gender, predisposing factors, duration of disease before admission, coma, temperature, MAP, WBC count and platelet count were significantly associated with the disease outcome (Table 1). No significant associations were found with race (Caucasian versus non-Caucasian; $\mathrm{p}=1.00$ ), the administration of antibiotics immediately before admission $(p=0.19)$, seizures $(p=0.09)$ and haemorrhagic skin lesions $(p=0.32)$.

In the multivariate analysis, age, gender, coma, temperature, MAP, WBC count and platelet count were independent determinants of the disease outcome (Table 1). The presence of coma on admission, temperature $\leqslant 38.0^{\circ} \mathrm{C}$, MAP $\leqslant 70 \mathrm{mmHg}$, WBC count $\leqslant 10 \times 10^{9} / \mathrm{L}$ and platelet count $\leqslant 100 \times 10^{9} / \mathrm{L}$ increased the risk of a fatal outcome (ORs 5.1, 2.9, 3.0, 3.3 and 6.8 , respectively). Children aged $0-5$ months, teenagers aged 10-19 years and adult patients aged $\geqslant 50$ years had an increased risk of a fatal outcome compared with patients aged 6 months -9 years (ORs $4.7,3.7$ and 16.3 , respectively). In the multivariate analysis, gender was still associated with prognosis; females had an enhanced risk of dying of MD $(\mathrm{OR}=2.5)$.

The other candidates for inclusion in the logistic model (predisposing factors, duration of disease before admission, the administration of antibiotics immediately before admission and seizures) were no longer associated with the disease outcome in the multivariate analysis. Patients with a predisposing factor $(\mathrm{n}=25)$ were older and presented more often with a low WBC count or a low platelet count, or both. A short duration of disease before admission $(<1$ day; $\mathrm{n}=111$ ) occurred more frequently in patients with a low MAP, low WBC count or a low platelet count, or any combination of these. Antibiotics were administered immediately before admission to only 11 patients. Patients presenting with seizures $(n=24)$ were more likely to have a low MAP.

The number of missing values for the variables coma, temperature, MAP, WBC count and platelet count were $14,19,97,84$ and 147 , respectively. For these variables, indicator terms, which indicated the presence or absence of information about the corresponding variables were used in the logistic model. With 
Table 1. Distribution of fatalities and case fatality rate (CFR) among indicated variables, and univariate and multivariate* odds ratios (ORs) of a fatal disease outcome (reference category: $O R=1.0$ ) and their $95 \%$ confidence intervals $(95 \% \mathrm{CIs})$

\begin{tabular}{|c|c|c|c|c|c|c|}
\hline \multirow[b]{2}{*}{ Variable } & \multicolumn{4}{|c|}{ Univariate analysis } & \multicolumn{2}{|c|}{ Multivariate analysis } \\
\hline & $\begin{array}{l}\text { Number of fatal } \\
\text { cases/Total }\end{array}$ & CFR (\%) & OR & $95 \% \mathrm{CI}$ & $\mathrm{OR}^{*}$ & $95 \% \mathrm{CI}$ \\
\hline \multicolumn{7}{|l|}{ Age } \\
\hline $0-5$ months & $4 / 24$ & $(16.7)$ & 5.6 & $1.2-21.4$ & 4.7 & $1.0-22.6$ \\
\hline 6 months -9 years & $10 / 289$ & $(3.5)$ & 1.0 & & 1.0 & \\
\hline $10-19$ years & $16 / 156$ & $(10.3)$ & 3.2 & $1.4-7.2$ & 3.7 & $1.4-10.2$ \\
\hline $20-49$ years & $2 / 56$ & (3.6) & 1.0 & $0.1-5.1$ & 0.7 & $0.1-4.1$ \\
\hline$\geqslant 50$ years & $11 / 37$ & $(29.7)$ & 11.8 & $4.1-33.8$ & 16.3 & $4.8-55.7$ \\
\hline \multicolumn{7}{|l|}{ Gender } \\
\hline Female & $30 / 267$ & $(11.2)$ & 2.7 & $1.4-5.4$ & 2.5 & $1.1-5.6$ \\
\hline Male & $13 / 295$ & $(4.4)$ & 1.0 & & 1.0 & \\
\hline \multicolumn{7}{|l|}{ Race } \\
\hline Non-Caucasian & $5 / 68$ & (7.4) & 1.0 & $0.3-2.7$ & & \\
\hline Caucasian & $35 / 483$ & $(7.2)$ & 1.0 & & & \\
\hline \multicolumn{7}{|l|}{ Predisposing factors } \\
\hline Present & $5 / 25$ & $(20.0)$ & 3.5 & $1.0-10.3$ & & \\
\hline Absent & $35 / 522$ & $(6.7)$ & 1.0 & & & \\
\hline \multicolumn{7}{|l|}{$\begin{array}{l}\text { Duration of disease } \\
\text { before admission }\end{array}$} \\
\hline$<1$ day & $14 / 111$ & $(12.6)$ & 2.3 & $1.2-4.7$ & & \\
\hline$\geqslant 1$ day & $25 / 432$ & $(5.8)$ & 1.0 & & & \\
\hline \multicolumn{7}{|l|}{$\begin{array}{l}\text { Prior administration } \\
\text { of antibiotics }\end{array}$} \\
\hline Yes & $2 / 11$ & $(18.2)$ & 2.9 & $0.3-14.5$ & & \\
\hline No & $39 / 541$ & $(7.2)$ & 1.0 & & & \\
\hline \multicolumn{7}{|l|}{ Coma } \\
\hline Present & $10 / 43$ & $(23.3)$ & 4.8 & $1.9-11.2$ & 5.1 & $2.2-11.9$ \\
\hline Absent & $30 / 505$ & (5.9) & 1.0 & & 1.0 & \\
\hline \multicolumn{7}{|l|}{ Seizures } \\
\hline Present & $4 / 24$ & $(16.7)$ & 2.6 & $0.6-8.5$ & & \\
\hline Absent & $37 / 527$ & $(7.0)$ & 1.0 & & & \\
\hline \multicolumn{7}{|c|}{ Haemorrhagic skin lesions } \\
\hline Present & $29 / 355$ & $(8.2)$ & 1.4 & $0.7-3.0$ & & \\
\hline Absent & $11 / 189$ & (5.8) & 1.0 & & & \\
\hline \multicolumn{7}{|l|}{ Temperature } \\
\hline$\leqslant 38.0^{\circ} \mathrm{C}$ & $13 / 98$ & $(13.3)$ & 2.7 & $1.3-5.5$ & 2.9 & $1.2-7.0$ \\
\hline$>38.0^{\circ} \mathrm{C}$ & $24 / 445$ & $(5.4)$ & 1.0 & & 1.0 & \\
\hline \multicolumn{7}{|c|}{ Mean arterial pressure } \\
\hline$\leqslant 70.0 \mathrm{mmHg}$ & $17 / 125$ & $(13.6)$ & 3.0 & $1.5-6.1$ & 3.0 & $1.2-7.9$ \\
\hline$>70.0 \mathrm{mmHg}$ & $17 / 340$ & $(5.0)$ & 1.0 & & 1.0 & \\
\hline \multicolumn{7}{|c|}{ White blood cell count } \\
\hline$\leqslant 10 \times 10^{9} / \mathrm{L}$ & $18 / 113$ & $(15.9)$ & 5.1 & $2.4-10.8$ & 3.3 & $1.3-8.6$ \\
\hline$>10 \times 10^{9} / \mathrm{L}$ & $13 / 365$ & $(3.6)$ & 1.0 & & 1.0 & \\
\hline \multicolumn{7}{|l|}{ Platelet count } \\
\hline$\leqslant 100 \times 10^{9} / \mathrm{L}$ & $12 / 38$ & $(31.6)$ & 11.1 & $4.2-28.3$ & 6.8 & $2.2-20.4$ \\
\hline$>100 \times 10^{9} / \mathrm{L}$ & $15 / 377$ & $(4.0)$ & 1.0 & & 1.0 & \\
\hline
\end{tabular}

${ }^{*}$ Estimated in a model with missing indicators (see Table 2).

information present as reference category, the ORs of these indicator variables were all $>1$ (Table 2), indicating increased risk for a fatal outcome in the absence of information. Only the OR for the missing indicator of temperature was significant $(p=0.01)$.

\section{Discussion}

Since 1958, meningococcal isolates from the blood or CSF, or both, of patients with MD have been submitted to the RLBM by almost all microbiologists in the 
Table 2. Distribution of fatalities, case fatality rate (CFR) and multivariate* odds ratios (ORs) of a fatal disease outcome of indicators of availability of information on corresponding variable (reference category: OR $=1.0$ ) and their $95 \%$ confidence intervals $(95 \%$ CIs)

\begin{tabular}{|c|c|c|c|c|c|}
\hline $\begin{array}{l}\text { Missing indicator of indicated } \\
\text { variable }\end{array}$ & $\begin{array}{l}\text { Number of fatal } \\
\text { cases/Total }\end{array}$ & CFR $(\%)$ & $\mathrm{OR}^{*}$ & $95 \% \mathrm{CI}$ & $\mathrm{p}$ value \\
\hline \multicolumn{6}{|l|}{ Coma } \\
\hline Information absent & $3 / 14$ & $(21.4)$ & 1.1 & $0.1-8.0$ & 0.94 \\
\hline Information present & $40 / 548$ & (7.3) & 1.0 & & \\
\hline \multicolumn{6}{|l|}{ Temperature } \\
\hline Information absent & $6 / 19$ & $(31.6)$ & 16.1 & $2.0-126.5$ & 0.01 \\
\hline Information present & $37 / 543$ & $(6.8)$ & 1.0 & & \\
\hline \multicolumn{6}{|l|}{ Mean arterial pressure } \\
\hline Information absent & 9/97 & $(9.3)$ & 1.1 & $0.3-4.5$ & 0.89 \\
\hline Information present & $34 / 465$ & (7.3) & 1.0 & & \\
\hline \multicolumn{6}{|l|}{ White blood cell count } \\
\hline Information absent & $12 / 84$ & $(14.3)$ & 2.4 & $0.6-9.0$ & 0.20 \\
\hline Information present & $31 / 478$ & $(6.5)$ & 1.0 & & \\
\hline \multicolumn{6}{|l|}{ Platelet count } \\
\hline Information absent & $16 / 147$ & $(10.9)$ & 2.2 & $0.7-7.1$ & 0.19 \\
\hline Information present & $27 / 415$ & $(6.5)$ & 1.0 & & \\
\hline
\end{tabular}

*Estimated in the full logistic model of Table 1.

Netherlands for further classification. In a previous study, the coverage rate of the submissions was calculated to be $>80 \%$ of the actual number of cases, whereas statutory notifications in the Netherlands accounted for only $58 \%$ [20]. Therefore, a high level of representation has been reached with the RLBM submission system. As a result of the intense involvement of the Dutch clinical microbiologists and specialists during the study period, the coverage rate might have been even higher, but it is beyond doubt that cases have been missed. This might pertain particularly to severely ill patients, among whom diagnostic procedures are prone to errors due to the seriousness of their condition. The present study was based on culture-proven cases only and, consequently, severely ill patients might be under-represented. However, it is not very likely that there was a differential under-reporting (e.g., fatal cases with low WBC count were more likely not to be reported). Therefore, we consider our data valid.

In this study, data were provided by many different attending specialists and some information bias can be expected. However, most questions were easily interpretable and pertained to substantive and easily obtainable data.

For the analysis, no distinction of the clinical picture into meningitis or bacteraemia was made, because it is determined by the various signs, symptoms and laboratory parameters. The latter are easier to assess than the clinical picture. Another reason for not including the clinical picture in the analysis is the inevitable induction of colinearity. However, the CFRs for patients with meningitis, bacteraemia and both meningitis and bacteraemia were $4.6 \%, 11.4 \%$ and $12.2 \%$, respectively [17].
In this large series of 562 patients with MD reported in the Netherlands during a 13-month period, age, gender, coma, temperature, MAP, WBC count and platelet count were independent prognostic indicators of the outcome. These findings are in agreement with those of other studies $[6,7,9,11-14]$. The presence of coma on admission, temperature $\leqslant 38.0^{\circ} \mathrm{C}$, MAP $\leqslant 70 \mathrm{mmHg}$, WBC count $\leqslant 10 \times 10^{9} / \mathrm{L}$ and platelet count $\leqslant 100 \times 10^{9} / \mathrm{L}$ were signs of a poor prognosis. Furthermore, the risk of a fatal outcome of MD was increased for patients aged 0-5 months, 10-19 years and $\geqslant 50$ years, and for female patients. However, it should be noted that the lower confidence limit of the $95 \%$ CIs for several variables was between 1.0 and 1.5 , indicating a relative lack of confidence in their significance. The prognostic power of these variables should be interpreted with care.

There seems to be a plausible explanation for most of these findings. Coma on admission or a low MAP, or both, can be regarded as signs of an already serious clinical picture of $\mathrm{MD}$, whereas a low temperature or a low WBC count, or both, presumably indicate poor defence mechanisms. A low platelet count seems to be an early sign of disseminated intravascular coagulation. The higher risk of a fatal outcome in patients $\geqslant 50$ years old can be explained partially at least by the higher incidence of either the measurable or the non-measurable predisposing factors in this age group, and immaturity of the immune system is the most likely explanation of the increased risk of death for infants. The increased risk for teenagers might be related to a temporal deficit of the non-specific immunity due to a change in life style during puberty [21]. However, there seems to be no sound explanation for the increased risk of a fatal outcome in female patients. An excess of deaths in female patients was 
also present in a previously reported analysis of the relationship between strain characteristics of $N$. meningitidis and disease outcome [17]. Sex-specific mortality of MD has been mentioned rarely in the literature $[2-4,7,11,13]$. The CFR was higher for males than for females in three reports $[2,3,11]$, whereas an excess of deaths in females was mentioned in three other reports $[4,7,13]$. These results were obtained by univariate analysis. Therefore, confounding by other factors such as age, cannot be ruled out. Recently, an excess of deaths in females among patients suffering from measles was shown by Garenne in an extensive review on this subject [22]. $\mathrm{He}$ assumed that biological (hormonal) factors increased the risk of a fatal outcome for females, which seems plausible.

In the univariate analysis, predisposing factors, duration of disease before admission, the administration of antibiotics immediately prior to admission and seizures were associated with the outcome of MD, but these associations disappeared in the multivariate analysis. The univariate associations seem to be explained almost completely by one or more of the other determinants. Another explanation for the disappearance of the univariate associations might be lack of statistical efficiency because of the uneven distribution of cases over the categories of three of the above-mentioned variables, with very small numbers in one of the categories.

The lack of association of haemorrhagic skin lesions with the disease outcome was remarkable. These lesions are generally found to be a bad prognostic sign $[6,7,9,11,13-15]$. No distinction was made in the questionnaire between the apparently less harmful petechial lesions and the ominous purpuric lesions. In addition, the majority of cases presented with these broadly defined haemorrhagic skin lesions. This might have impeded the recognition of the prognostic properties of these lesions in this study.

Of the ORs of the indicator variables for the availability of information, only the OR for the indicator of temperature was significant. However, all these ORs were $>1$, indicating an increased risk for a fatal outcome in the absence of information. It is likely that diagnostic procedures concerning severely ill patients are prone to errors and the omission of a basic measurement like temperature might pertain predominantly to patients who are admitted in a very bad condition.

The assessment of age, gender, coma, temperature, MAP, WBC count and platelet count on admission to hospital of patients with MD is an important means of identifying patients with a poor prognosis. This determination of high risk patients may result in prompt transfer of these patients to an intensive care unit. Their poor prognosis might benefit from early intensive treatment.

The authors wish to thank all medical microbiologists in the Netherlands for submitting bacterial isolates to the Reference Laboratory, and all specialists for their kind co-operation. We are most grateful to Professor J. van der Meer for his detailed commentary on the manuscript. This work was partially supported by a grant from the Praeventiefonds (grant number 28-1874).

\section{References}

1. Schwartz B, Moore PS, Broome CV. Global epidemiology of meningococcal disease. Clin Microbiol Rev 1989; 2 Suppl: S118-124.

2. Andersen B.M. Mortality in meningococcal infection. Scand $J$ Infect Dis 1978; 10: 227-282.

3. De Wals P, Hertoghe L, Reginster G et al. Mortality in meningococcal disease in Belgium. $J$ Infect 1984; 8: 264-273.

4. Spanjaard L, Bol P, De Marie S, Zanen HC. Association of meningococcal serogroups with the course of disease in the Netherlands, 1959-83. Bull World Health Organ 1987; 65: 861-868.

5. Havens PL, Garland, JS, Brook MM, Dewitz BA, Stremski ES, Troshynski TJ. Trends in mortality in children hospitalized with meningococcal infections, 1957 to 1987 . Pediatr Infect Dis $J$ 1989; 8: 8-11.

6. Tesoro LJ, Selbst, SM. Factors affecting outcome in meningococcal infections. Am J Dis Child 1991; 145: 218-220.

7. Fakhir S, Ahmad SH, Ahmad P. Prognostic factors influencing mortality in meningococcal meningitis. Ann Trop Paediatr 1992; 12: 149-154.

8. Palmer SR, Corson J, Hall $\mathrm{R}$ et al. Meningococcal disease in Wales: clinical features, outcome and public health management. $J$ Infect 1992; 25: 321-328.

9. Algren JT, Lal S, Cutliff SA, Richman BJ. Predictors of outcome in acute meningococcal infection in children. Crit Care Med 1993; 21: 447-452.

10. Baraff LJ, Lee SI, Schriger DL. Outcomes of bacterial meningitis in children: a meta-analysis. Pediatr Infect Dis $J$ 1993; 12: 389-394.

11. Olivares R, Bouyer J, Hubert B. Risk factors for death in meningococcal disease. Path Biol 1993; 41: 164-168.

12. Stiehm ER, Damrosch DS. Factors in the prognosis of meningococcal infection. Review of 63 cases with emphasis on recognition and management of the severely ill patient. $J$ Pediatr 1966; 68: 457-467.

13. Niklasson P-M, Lundbergh P, Strandell T. Prognostic factors in meningococcal disease. Scand J Infect Dis 1971; 3: 17-25.

14. Gedde-Dahl TW, Bjark P, Høiby EA, Høst JH, Bruun JN. Severity of meningococcal disease: assessment by factors and scores and implications for patient management. Rev Infect Dis 1990; 12: 973-992.

15. Tüysüz B, Özlü I, Aji DY, Erginel A. Prognostic factors in meningococcal disease and a new scoring system. Acta Paediatr 1993; 82: 1053-1056.

16. Scholten RJPM, Bijlmer HA, Poolman JT et al. Meningococcal disease in the Netherlands, 1958-1990. A steady increase in the incidence since 1982 partially caused by new serotypes and subtypes of Neisseria meningitidis. Clin Infect Dis 1993; 16: 237-246.

17. Scholten RJPM, Bijlmer HA, Valkenburg HA, Dankert J. Patient and strain characteristics in relation to the outcome of meningococcal disease: a multivariate analysis. Epidemiol Infect 1994; 112: 115-124.

18. Scholten RJPM, Kuipers B, Valkenburg HA, Dankert J, Zollinger WD, Poolman JT. Lipo-oligosaccharide immunotyping of Neisseria meningitidis by a whole-cell ELISA with monoclonal antibodies. J Med Microbiol 1994; 41: 236-243.

19. Miettinen OS. Theoretical epidemiology: principles of occurrence research in medicine. New York, Wiley. 1985: 231-233.

20. Spanjaard L, Bol P, Ekker W, Zanen HC. The incidence of bacterial meningitis in the Netherlands - a comparison of three registration systems, 1977-1982. J Infect 1985; 11: 259-268.

21. Mims CA. The pathogenesis of infectious disease. London, Academic Press. 1987.

22. Garenne M. Sex differences in measles mortality: a world review. Int $J$ Epidemiol 1994; 23: 632-642. 